\title{
Aptamer-Modified Gold Nanoparticles for Colorimetric Determination of Platelet-Derived Growth Factors and Their Receptors
}

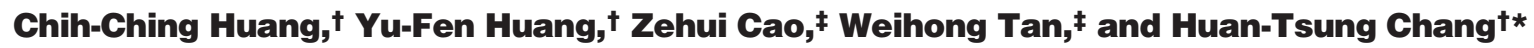 \\ Department of Chemistry, National Taiwan University, 1, Section 4, Roosevelt Road, Taipei, Taiwan, and Department of \\ Chemistry and Shands Cancer Center, McKnight Brain Institute, University of Florida, Gainesville, Florida 32611-7200
}

We have developed a highly specific sensing system for platelet-derived growth factors (PDGFs) and plateletderived growth factor receptors (PDGFR) that uses gold nanoparticles (GNPs). We synthesized GNPs modified with an aptamer (Apt-GNPs) that is specific to PDGFs and used them to detect PDGFs by monitoring the changes in the color and extinction of the Apt-GNPs that occur as a result of aggregation. The color of the Apt-GNPs changes from red to purple at low concentrations $(<400 \mathrm{nM})$, but changes only slightly at higher concentrations ( $>400 \mathrm{nM})$. We found that the sensitivity of the Apt-GNPs for the three PDGFs is highly salt-dependent, with an optimum condition of $200 \mathrm{mM} \mathrm{NaCl}$. We obtained biphasic curves when plotting of the ratios of the extinction coefficients of the Apt-GNPs at 650 and $530 \mathrm{~nm}$ against the concentrations of PDGF-AA at various concentrations of Apt-GNPs. The linear ranges of the increases and decreases in this extinction ratio are $2.5-10$ and $10-20 \mathrm{nM}$, respectively, for $0.42 \mathrm{nM}$ Apt-GNPs and 25-75 and 75-200 nM, respectively, for 8.4 $\mathrm{nM}$ Apt-GNPs. When using $8.4 \mathrm{nM}$ Apt-GNPs, the corresponding linear ranges of the increases and decreases in this extinction ratio are 15-100 and 100-400 nM, respectively, for PDGF-AB and 35150 and 150-400 nM, respectively, for PDGF-BB. In addition, we have developed a homogeneous assay to detect the PDGF receptor- $\beta$ (PDGFR- $\beta$ ) at concentrations as low as $3.2 \mathrm{nM}$, on the basis of the competition between the Apt-GNPs and PDGFR- $\beta$ for PDGF-BB. The results we present in this paper imply that there are practical applications of Apt-GNPs in protein analysis and cancer diagnosis.

Metal nanoparticles, which possess strongly distance-dependent optical properties and large surface areas, have emerged as important colorimetric materials. ${ }^{1}$ For example, with the extinction coefficients of their surface plasmon absorption bands being over 1000 times larger than those of organic dyes, as well as their sizeand shape-dependent optical properties, ${ }^{2}$ gold nanoparticle (GNP)based molecular recognition approaches provide sensitivity and

\footnotetext{
* To whom correspondence should be addressed. Telfax: 011-886-2-23621963 E-mail: changht@ntu.edu.tw.

$\dagger$ National Taiwan University.

‡ University of Florida.
}

selectivity that are comparable to those of fluorescence techniques. ${ }^{1}$ Commonly, the sensing mechanism is based on GNP aggregation, which causes color changes that are due to both electronic dipole-dipole coupling between neighboring particles and scattering. ${ }^{3}$ Dispersed GNPs having interparticle distances substantially greater than their average particle diameter appear red, whereas the color of the aggregates changes to purple as the interparticle distance drops below the average particle diameter. ${ }^{1}$ GNP aggregation-based sensors have been demonstrated for detecting duplex DNA formation, ${ }^{4}$ protein-ligand interactions, ${ }^{5}$ antigen-antibody recognitions, ${ }^{1 e, 1,6}, 6$ and metal ionligand complexation. ${ }^{1 c, 1 d, 3 c}$ Recently, an aqueous solution of 32$\mathrm{nm}$ gold nanoparticles (GNPs), to which Nile Red (NR) was adsorbed noncovalently, was used for the sensing of aminothiols.? The as-prepared NRGNPs fluoresce weakly as a result of fluorescence resonance energy transfer between NR and the GNPs. The fluorescence of a solution containing NRGNPs at pH 4.0 increases upon the addition of aminothiols. By conducting fluorescence and colorimetric assays, cationic, neutral, and anionic aminothiols can be differentiated.

(1) (a) Storhoff, J. J.; Elghanian, R.; Mucic, R. C.; Mirkin, C. A.; Letsinger, R. L. J. Am. Chem. Soc. 1998, 120, 1959-1964. (b) Otsuka, H.; Akiyama, Y.; Nagasaki, Y.; Kataoka, K. J. Am. Chem. Soc. 2001, 123, 8226-8230. (c) Lin, S.-Y.; Liu, S.-W.; Lin, C.-M.; Chen, C.-H. Anal. Chem. 2002, 74, 330335. (d) Obare, S. O.; Hollowell, R. E.; Murphy, C. J. Langmuir 2002, 18 , 10407-10410. (e) Thanh, N. T. K.; Rosenzweig, Z. Anal. Chem. 2002, 74, 1624-1628. (f) Hirsch, L. R.; Jackson, J. B.; Lee, A.; Halas, N. J.; West, J. L. Anal. Chem. 2003, 75, 2377-2381.

(2) (a) Mulvaney, P. Langmuir 1996, 12, 788-800. (b) Link, S.; Mohamed, M. B.; El-Sayed, M. A. J. Phys. Chem. B 1999, 103, 3073-3077. (c) Kelly, K. L.; Coronado, E.; Zhao, L. L.; Schatz, G. C. J. Phys. Chem. B 2003, 107 , 668-677.

(3) (a) Sandrock, M. L.; Foss, C. A., Jr. J. Phys. Chem. B 1999, 103, 1139811406. (b) Storhoff, J. J.; Lazarides, A. A.; Mucic, R. C.; Mirkin, C. A.; Letsinger, R. L.; Schatz, G. C. J. Am. Chem. Soc. 2000, 122, 4640-4650. (c) Norsten, T. B.; Frankamp, B. L.; Rotello, V. M. Nano Lett. 2002, 2, 1345-1348. (d) Grant, C. D.; Schwartzberg, A. M.; Norman, T. J., Jr.; Zhang, J. Z. J. Am. Chem. Soc. 2003, 125, 549-553.

(4) (a) Mirkin, C. A.; Letsinger, R. L.; Mucic, R. C.; Storhoff, J. J. Nature 1996 , 382, 607-609. (b) Elghanian, R.; Storhoff, J. J.; Mucic, R. C.; Letsinger, R. L.; Mirkin, C. A. Science 1997, 277, 1078-1081. (c) Reynolds, R. A., III.; Mirkin, C. A.; Letsinger, R. L. J. Am. Chem. Soc. 2000, 122, 3795-3796.

(5) (a) Park, S.-J.; Lazarides, A. A.; Mirkin, C. A.; Letsinger, R. L. Angew. Chem. Int. Ed. 2001, 40, 2909-2912. (b) Nam, J.-M.; Park, S.-J.; Mirkin, C. A. J. Am. Chem. Soc. 2002, 124, 3820-3821. (c) Cobbe, S.; Connolly, S.; Ryan, D.; Nagle, L.; Eritja, R.; Fitzmaurice, D. J. Phys. Chem. B 2003, 107, 470477. (d) Costanzo, P. J.; Patten, T. E.; Seery, T. A. P. Chem. Mater. 2004, 16, 1775-1785.

(6) Shenton, W.; Davis, S. A.; Mann, S. Adv. Mater. 1999, 11, 449-452.

(7) Chen, S.-J.; Chang, H.-T. Anal. Chem. 2004, 76, 3727-3734. 
As complements to antibody-based sensors, molecular probes based on nucleic acid platforms are emerging. DNA and RNA sequences that recognize specific target analytes are called aptamers; they can be obtained through combinatorial biological approaches, such as the systematic evolution of ligands by exponential enrichment (SELEX) ${ }^{8,9}$ In comparison to antibodies, aptamers possess certain advantages, including their relatively simple and inexpensive syntheses through automation, tolerance to internal labeling, and long storage times without altering or losing their biological properties. Aptamers have been used successfully in many applications, including flow cytometry; ${ }^{10}$ biosensors; ${ }^{11}$ ELISA-type assays; ${ }^{12}$ and separations, such as capillary electrochromatography and affinity chromatography. ${ }^{13}$ Aptamerfunctionalized $\mathrm{Au}$ nanoparticles have been applied to the determination of thrombin using a quartz crystal microbalance; the sensitivity limit corresponded to a concentration of $2 \mathrm{nM} .{ }^{11 \mathrm{~d}}$

Platelet-derived growth factor (PDGF) is a growth factor protein found in human platelets; it has growth-promoting activity toward fibroblasts, smooth muscle cells, and glial cells. ${ }^{14-17}$ There are three known PDGF isoforms-the so-called PDGF-AA, -BB, and $-\mathrm{AB}-$ that are homo- and heterodimers of related $\mathrm{A}$ and $\mathrm{B}$ polypeptide chains. ${ }^{15}$ The three isomeric PDGF molecules bind specifically and with different degrees to two receptors, namely, the PDGF $\alpha$ - and $\beta$-receptors. ${ }^{18}$ The dissociation constants $\left(K_{d}\right)$ for the complexes of PDGF receptor- $\alpha$ (PDGFR- $\alpha$ ) with PDGF$\mathrm{BB}, \mathrm{AB}$, and $-\mathrm{AA}$ are $0.5,0.1$, and $0.2 \mathrm{nM}$, respectively. ${ }^{19}$ Although PDGFR- $\beta$ binds both PDGF-BB and PDGF-AB with high affinity

(8) (a) Joyce, G. F. Gene 1989, 82, 83-87. (b) Ellington, A. D.; Szostak, J. W. Nature 1990, 346, 818-822. (c) Tuerk, C.; Gold, L. Science 1990, 249, 505-510.

(9) (a) Sassanfar, M.; Szostak, J. W. Nature 1993, 364, 550-553. (b) Famulok, M. J. Am. Chem. Soc. 1994, 116, 1698-1706. (c) Jenison, R. D.; Gill, S. C.; Pardi, A.; Polisky, B. Science 1994, 263, 1425-1429. (d) Nieuwlandt, D.; Wecker, M.; Gold, L. Biochemistry 1995, 34, 5651-5659. (e) Williams, K. P.; Liu, X.-H.; Schumacher, T. N. M.; Lin, H. Y.; Ausiello, D. A.; Kim, P. S.; Bartel, D. P. Proc. Natl. Acad. Sci. U.S.A. 1997, 94, 11285-11290.

(10) (a) Davis, K. A.; Abrams, B.; Lin, Y.; Jayasena. S. D. Nucleic Acids Res. 1996 , 24, 702-706. (b) Davis, K. A.; Lin, Y.; Abrams, B.; Jayasena, S. D. Nucleic Acids Res. 1998, 26, 3915-3924.

(11) (a) Kleinjung, F.; Klussmann, S.; Erdmann, V. A.; Scheller, F. W.; Fürste, J. P.; Bier, F. F. Anal. Chem. 1998, 70, 328-331. (b) Potyrailo, R. A.; Conrad, R. C.; Ellington, A. D.; Hieftje, G. M. Anal. Chem. 1998, 70, 3419-3425. (c) Liss, M.; Petersen, B.; Wolf, H.; Prohaska, E. Anal. Chem. 2002, 74, 4488-4495. (d) Pavlov, V.; Xiao, Y.; Shlyahovsky, B.; Willner, I. J. Am. Chem. Soc. 2004, 126, 11768-11769. (e) Farokhzad, O. C.; Jon, S.; Khademhosseini, A.; Tran, T.-N. T.; La Van, D. A.; Langer, R. Cancer Res. 2004, 64, 7668-7672.

(12) Drolet, D. W.; Moon-McDermott, L.; Romig, T. S. Nat. Biotechnol. 1996 , 14, 1021-1025.

(13) (a) German, I.; Buchanan, D. D.; Kennedy R. T. Anal. Chem. 1998, 70, 4540-4545. (b) Rehder, M. A.; McGown, L. B. Electrophoresis 2001, 22, 3759-3764. (c) Deng, Q.; German, I.; Buchanan, D.; Kennedy, R. T. Anal. Chem. 2001, 73, 5415-5421. (d) Buchanan, D. D.; Jameson, E. E.; Perlette, J.; Malik, A.; Kennedy R. T. Electrophoresis 2003, 24, 1375-1382. (e) Berezovski, M.; Nutiu, R.; Li, Y.; Krylov S. N. Anal. Chem. 2003, 75, 13821386.

(14) (a) Kohler, N.; Lipton, A. Exp. Cell Res. 1974, 87, 297-301. (b) Ross, R.; Glomset, J.; Kariya, B.; Harker, L. Proc. Natl. Acad. Sci. U.S.A. 1974, 71, 1207-1210. (c) Westermark, B.; Wasteson, A. Exp. Cell Res. 1976, 98, 170174. (d) Lubinus, M.; Meier, K. E.; Smith. E. A.; Gause, K. C.; LeRoy, E. C.; Trojanowska, M. J. Biol. Chem. 1994, 269, 9822-9825. (e) Lindner, V.; Giachelli, C. M.; Schwartz, S. M.; Reidy, M. A. Circ. Res. 1995, 76, 951957. (f) Gard, A. L.; Burrell, M. R.; Pfeiffer, S. E.; Rudge, J. S.; Williams, W. C., II. Development 1995, 121, 2187-2197.

(15) (a) Hammacher, A.; Hellman, U.; Johnsson, A.; Östman, A.; Gunnarsson, K.; Westermark, B.; Wasteson, A.; Heldin, C.-H. J. Biol. Chem. 1988, 263, 16493-16498. (b) Hart, C. E.; Bailey, M.; Curtis, D. A.; Osborn, S.; Raines, E.; Ross, R.; Forstrom J. W. Biochemistry 1990, 29, 166-172.
$\left(K_{\mathrm{d}}=0.5 \mathrm{pM}\right.$ and $1-2.5 \mathrm{nM}$, respectively), it has no appreciable affinity for PDGF-AA. ${ }^{19}$ Binding of the receptors to PDGF is known to activate intracellular tyrosine kinase, leading to autophosphorylation of the cytoplasmic domain of the receptor as well as phosphorylation of other intracellular substrates. ${ }^{20}$ In view of its importance, traditional antibody-based radioisotopic methods and ELISA techniques have been developed for the detection of PDGF. ${ }^{21}$ Antibodies to PDGF are the most potent and specific antagonists of PDGF. ${ }^{22}$ The known inhibitors of PDGF include suramin, ${ }^{23}$ neomycin, ${ }^{24}$ and peptides ${ }^{25}$ derived from the PDGF amino acid sequence, but either they are too toxic or they lack sufficient specificity for practical applications. To overcome these disadvantages, a fluorophore-labeled aptamer and an aptamer labeled with both a fluorophore and a quencher have been used to determine PDGF on the basis of fluorescence anisotropy and energy transfer, respectively. ${ }^{26,27}$

We have designed a colorimetric biosensor for the simple and specific detection of PDGF and PDGFR that uses an aptamermodified GNP (Apt-GNP) as a probe. The consensus secondary structure motif of the PDGF aptamer is a three-way helix junction with a conserved single-stranded loop at the branch point, in which the helix junction domain represents the core of the structural motif required for high-affinity binding. The aptamer has comparable affinities $\left(K_{\mathrm{d}} \sim 0.1 \mathrm{nM}\right)$ to PDGF-BB and PDGF-AB, which are higher than that $\left(K_{\mathrm{d}}>10 \mathrm{nM}\right)$ to PDGF-AA. ${ }^{28}$ When PDGF

(16) (a) Evanko, S. P.; Raines, E. W.; Ross, R.; Gold, L. I.; Wight, T. N. Am. J. Pathol. 1998, 152, 533-546. (b) Jong, J. S. D.; Diest, P. J. V.; Valk, P. V. D.; Baak, J. P. A. J. Pathol. 1998, 184, 53-57. (c) Gajdos, M.; Mongiellova, V.; Huttova, D.; Cibulova, L.; Krivosikova, Z.; Spustova, V.; Dzurik, R. J. Cardiovasc. Pharmacol. 2001, 38, 651-656. (d) Bentas, W.; Beecken, W. D.; Glienke, W.; Binder, J.; Schuldes, H. Urol. Res. 2003, 30, 390-393. (e) Atkinson, S.; Fox, S. B. J. Pathol. 2004, 203, 721-728. (f) Apte, S. M.; Bucana, C. D.; Killion, J. J.; Gersherson, D. M.; Fidler, I. J. Gynecol. Oncol. 2004, 93, 78-86.

(17) (a) Yeh, H.-J.; Silos-Santiago, I.; Wang, Y.-X.; George, R. J.; Snider, W. D.; Deuel, T. F. Proc. Natl. Acad. Sci. U.S.A. 1993, 90, 1952-1956. (b) Lepistö, J.; Peltonen, J.; Vähä-Kreula, M.; Söderström, K.-O.; Niinikoski, J.; Laato, M. Cell Tissue Res. 1996, 286, 449-455. (c) Koempel, J. A.; Gibson, S. E.; O'Grady, K.; Toriumi, D. M. Int. J. Pediatr. Otorhinolaryngol. 1998, 46, 1-8. (d) Pelá, I. R.; Ferreira, M. E. S.; Melo, M. C. C.; Silva, C. A. A.; Coelho, M. M.; Valenzuela, C. F. Am. J. Physiol. Regul. Integr. Comput. Physiol. 2000, 278, R1275-R1281.

(18) Hart, C. E.; Forstrom, J. W.; Kelly, J. D.; Seifert, R. A.; Smith, R. A.; Ross, R.; Murray, M. J.; Bowen-Pope, D. F. Science 1988, 240, 1529-1531.

(19) (a) Seifert, R. A.; Koppen A. V.; Bowen-Pope, D. F. J. Biol. Chem. 1993, 268, 4473-4480. (b) Claesson- Welsh, L. J. Biol. Chem. 1994, 269, 3202332026. (c) Meyer-Ingold, W.; Eichner, W. Cell Biol. Int. 1995, 19, 389 398.

(20) (a) Bishayee, S.; Majumdar, S.; Scher, C. D.; Khan, S. Mol. Cell. Biol. 1988, 8, 3696-3702. (b) Keating, M. T.; Escobedo, J. A.; Williams, L. T. J. Biol. Chem. 1988, 263, 12805-12808

(21) (a) Singh, J. P.; Chaikin, M. A.; Stiles, C. D. J. Cell Biol. 1982, 95, 667671. (b) Bowen-Pope, D. F.; Malpass, T. W.; Foster, D. M.; Ross, R. Blood 1984, 64, 458-469. (c) Leitzel, K.; Bryce, W.; Tomita, J.; Manderino, G.; Tribby, I.; Thomason, A.; Billingsley, M.; Podczaski, E.; Harvey, H.; Bartholomew, M. Cancer Res. 1991, 51, 4149-4154. (d) Blaskovich, M. A.; Lin, Q.; Delarue, F. L.; Sun, J.; Park, H. S.; Coppola, D.; Hamilton, A. D.; Sebti, S. M. Nat. Biotechnol. 2000, 18, 1065-1070.

(22) (a) LaRochelle, W. J.; Robbins, K. C.; Aaronson, S. A. Mol. Cell Biol. 1989 9, 3538-3542. (b) Ferns, G. A. A.; Raines, E. W.; Sprugel, K. H.; Motani, A. S.; Reidy, M. A.; Ross, R. Science 1991, 253, 1129-1132.

(23) Betsholtz, C.; Westermark, B.; Ek, B.; Heldin, C.-H. Cell 1984, 39, 447457.

(24) Vassbotn, F. S.; Östman, A.; Siegbahn, A.; Holmsen, H.; Heldin, C.-H. J. Biol. Chem. 1992, 267, 15635-15641.

(25) Engström, U.; Engström, Å.; Ernlund, A.; Westermark, B.; Heldin, C.-H. J. Biol. Chem. 1992, 267, 16581-16587.

(26) Fang, X.; Cao, Z.; Beck, T.; Tan, W. Anal. Chem. 2001, 73, 5752-5757.

(27) Fang, X.; Sen, A.; Vicens, M.; Tan, W. ChemBioChem 2003, 4, 829-834. 
was introduced to the solution of Apt-GNPs, aggregation occurred to different degrees, depending on the PDGF concentration and the binding affinity of the aptamer toward the PDGF. The aggregation of Apt-GNPs is due to the fact that the aptamer binds to PDGF in a $2: 1$ fashion. ${ }^{28,29}$

\section{EXPERIMENTAL SECTION}

Materials. The $5^{\prime}$-thiol-modified aptamer having the sequence 5'-CAG GCT ACG GCA CGT AGA GCA TCA CCA TGA TCC TG$3^{\prime}$ and the oligonucleotide (control) having the sequence $5^{\prime}-\mathrm{CAG}$ CGT ACG GCA CGT ACC GAT TCA CCA TGA AGC TG-3' were purchased from Integrated DNA Technology, Inc. (Coralville, IA). Recombinant human PDGF-AA, PDGF-BB, PDGF-AB, PDGFR$\alpha$, and PDGFR- $\beta$ were purchased from $R \& D$ Systems Inc. (Minneapolis, MN). PDGFs were dissolved in $4 \mathrm{mM} \mathrm{HCl}$ containing $0.1 \%$ bovine serum albumin (BSA), whereas PDGFRs were prepared in $5 \mathrm{mM}$ PBS ( $\mathrm{pH} 7.4 ; 135 \mathrm{mM} \mathrm{NaCl}$ ). BSA, carbonic anhydrase (CA), trypsinogen (Try), and lysozyme (Lys) were obtained from Sigma (St. Louis, MO). Hydrogen tetrachloroaurate(III) trihydrate, poly (ethylene glycol) (PEG), poly (ethylene oxide) (PEO), poly ( $N$-vinyl-2-pyrrolidone) (PVP), and all other reagents used in this study were purchased from Aldrich (Milwaukee, WI).

Synthesis of GNPs. GNPs were prepared by citrate reduction of $\mathrm{HAuCl}_{4}{ }^{30}$ A $250-\mathrm{mL}$ aqueous solution consisting of $1 \mathrm{mM}$ $\mathrm{HAuCl}_{4}$ was brought to a vigorous boil with stirring in a roundbottom flask fitted with a reflux condenser, and then $38.8 \mathrm{mM}$ trisodium citrate $(25 \mathrm{~mL})$ was added rapidly to the solution. The solution was boiled for another $15 \mathrm{~min}$, during which time its color changed from pale yellow to deep red. The solution was cooled to room temperature with continuous stirring. The sizes of the nanoparticles were verified by TEM (H7100, Hitachi HighTechnologies Corporation, Tokyo, Japan); they appeared to be nearly monodisperse, with an average size of $13.3 \pm 1.2 \mathrm{~nm}$. The particle concentration of the GNPs was $\sim 15 \mathrm{nM}$, which was determined according to the Beer's law by using the extinction coefficient of $\sim 10^{8} \mathrm{M}^{-1} \mathrm{~cm}^{-1}$ for $13.3 \mathrm{~nm}$ GNPs in diameter at $520 \mathrm{~nm}^{30 \mathrm{c}}$

Preparation of Apt-GNPs. The two thiol-modified 35-mer DNA oligonucleotides were attached to the GNPs according to modified literature procedures. ${ }^{1}$ The $5^{\prime}$-thiol-modified oligonucleotides were received in a disulfide form $\left[\mathrm{HOCH}_{3}\left(\mathrm{CH}_{2}\right)_{5} \mathrm{~S}-\mathrm{S}-5^{\prime}\right.$ oligo], protected by a mercaptohexanol groups. These oligonucleotides were reacted directly with the GNPs through attachment of both the $\mathrm{HOCH}_{3}\left(\mathrm{CH}_{2}\right)_{5} \mathrm{~S}-$ and oligo-S- units onto the GNP surface (Scheme 1). Two aliquots of aqueous GNP solutions (800 $\mu \mathrm{L}$ ) in a $1.5-\mathrm{mL}$ tube were mixed separately with the thiooligonucleotides $(5.0 \mu \mathrm{M}, 200 \mu \mathrm{L})$ to obtain a final concentration of $12 \mathrm{nM}$ GNPs and $1.0 \mu \mathrm{M}$ oligonucleotides. After reaction for $24 \mathrm{~h}$ at room temperature, the mixtures were centrifuged for 25 min at $16000 \mathrm{rpm}$ to remove the excess thiol-DNA. Following removal of the supernatants, the oily precipitates were washed with $4 \mathrm{mM}$ trisodium citrate. After two wash/centrifuge cycles,

(28) Green, L. S.; Jellinek, D.; Jenison, R.; Östman, A.; Heldin, C.-H.; Janjic, N. Biochemistry 1996, 35, 14413-14424.

(29) Fredriksson, S.; Gullberg, M.; Jarvius, J.; Olsson, C.; Pietras, K.; Gústafsdóttir, S. M.; Östman, A.; Landegren, U. Nat. Biotechnol. 2002, 20, 473-477.

(30) (a) Frens, G. Nat. Phys. Sci. 1973, 241, 20-22. (b) Grabar, K. C.; Freeman, R. G.; Hommer, M. B.; Natan, M. J. Anal. Chem. 1995, 67, 735-743. (c) Mucic, R. C.; Storhoff, J. J.; Mirkin, C. A.; Letsinger, R. L. J. Am. Chem. Soc. 1998, 120, 12674-12675.
Scheme 1. Schematic Representation of Aptamer Molecules Linked to the Surfaces of GNPs
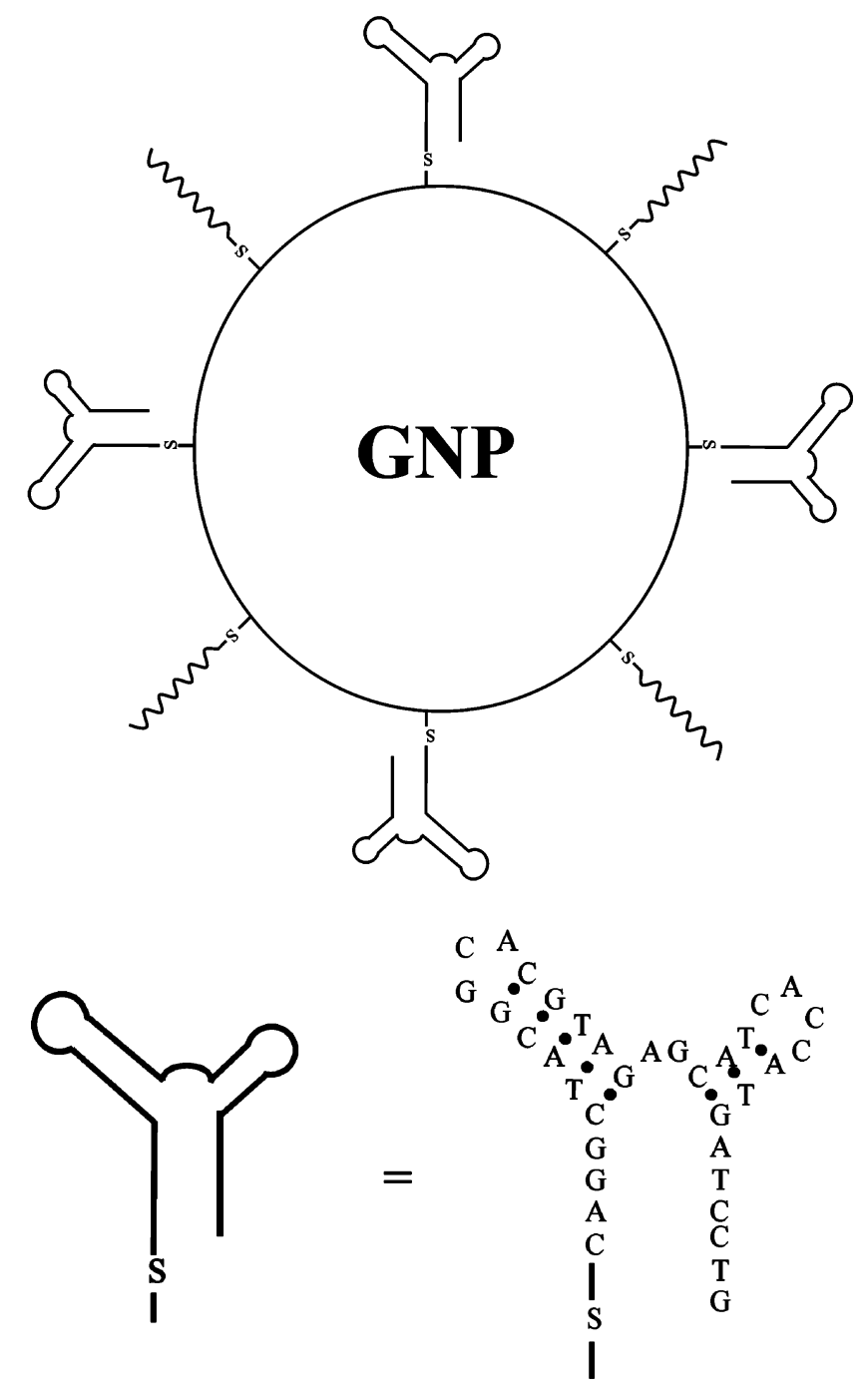

\section{$-\mathrm{S} \sim-\mathrm{S}-\mathrm{CH}_{2} \mathrm{CH}_{2} \mathrm{CH}_{2} \mathrm{CH}_{2} \mathrm{CH}_{2} \mathrm{CH}_{2} \mathrm{OH}$}

the colloids were resuspended separately in $4 \mathrm{mM}$ trisodium citrate and stored in a refrigerator $\left(4^{\circ} \mathrm{C}\right)$. Finally, the Apt-GNPs and oligo-GNPs (control) were equilibrated separately with $0.1 \%$ BSA for 120 min at room temperature before treating with PFGFs; the BSA-modified Apt-GNPs and oligo-GNPs were stable in solutions containing up to $3.0 \mathrm{M} \mathrm{NaCl}$. Scheme 1 displays a cartoon representation of the as-prepared Apt-GNPs. To determine the number of oligos on each gold nanoparticle, a solution of 2-mercaptoethanol $(1.0 \mathrm{M}, 10 \mu \mathrm{L})$ was used to displace the oligonucleotide molecules from the surface of the GNPs $(12 \mathrm{nM}$, $990 \mu \mathrm{L})$. The amount of displaced oligonucleotide in the supernatant was used to calculate its quantity on each GNP particle. Our calculations indicated that $\sim 42$ oligonucleotide molecules were attached to each GNP. ${ }^{1}$

Aggregation Assays. Aliquots (100 $\mu \mathrm{L})$ of 0.2 M PBS (200 $\mathrm{mM} \mathrm{NaCl}, 5 \mathrm{mM}$ sodium phosphate, $\mathrm{pH}$ 7.4) solutions containing PDGFs $(0-400 \mathrm{nM})$ in the presence of Apt-GNPs $(8.4 \mathrm{nM})$ or oligo-GNPs $(8.4 \mathrm{nM})$ were maintained at room temperature for 2 
A.

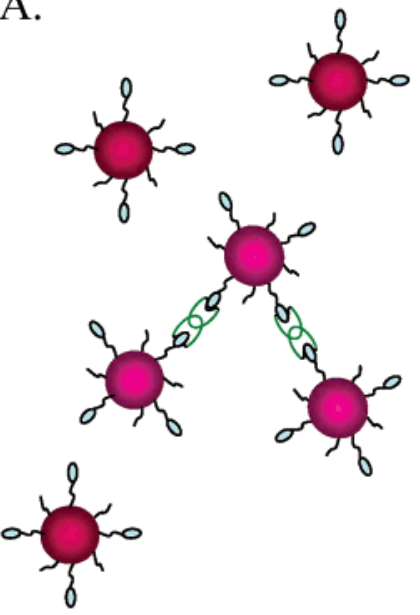

B.

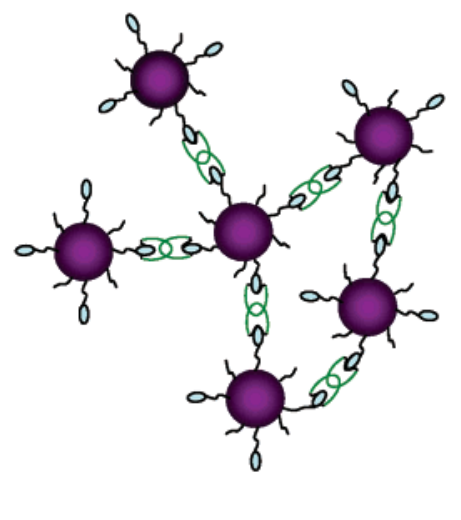

C.

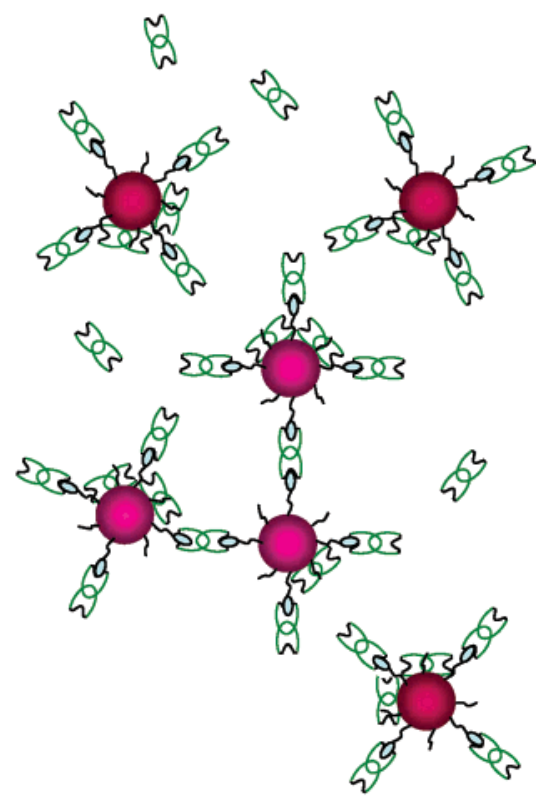

: GNPs $(13 \mathrm{~nm})$
: PDGF binding Aptamer

5'-/Thio/CAGGCTACGGCACGTAGAGCATCACCATGATCCTG-3'

$\sim$ : $-\mathrm{SCH}_{2} \mathrm{CH}_{2} \mathrm{CH}_{2} \mathrm{CH}_{2} \mathrm{CH}_{2} \mathrm{CH}_{2} \mathrm{OH}$

飞了: PDGF

h. All solutions were then transferred into a $100-\mu \mathrm{L}$ quartz cuvette, and their extinction coefficients were measured using a Cintra 10e UV-vis spectrophotometer (GBC, Victoria, Australia).

Competitive Assays of PDGF Receptor- $\boldsymbol{\beta}$. Aliquots $(100 \mu \mathrm{L})$ of $0.2 \mathrm{M}$ PBS (200 mM NaCl, $5 \mathrm{mM}$ sodium phosphate, $\mathrm{pH} 7.4$ ) solutions containing PDGFs $(0-400 \mathrm{nM})$ and Apt-GNPs $(8.4 \mathrm{nM})$ in the presence of PDGF receptor- $\beta(1-250 \mathrm{nM})$ were maintained at room temperature for $2 \mathrm{~h}$. All solutions were then transferred into separate $100-\mu \mathrm{L}$ quartz cuvettes, and their extinction coefficients were measured using a UV-vis spectrophotometer.

\section{RESULTS AND DISCUSSION}

Mechanism of PDGF-Induced Apt-GNP Aggregation. The Apt-GNP solutions changed color in the presence of PDGFs (Scheme 2). At low PDGF concentrations, no obvious aggregation was observed, presumably because interparticle cross-linking occurs to only a very low degree (Scheme 2A). When the concentration of the PDGFs was high enough to induce a greater degree of interparticle cross-linking, we observed aggregation of Apt-GNPs to a greater extent (Scheme 2B). In this case, we believe that PDGF molecules act as bridges that link Apt-GNPs together, with one PDGF molecule joining two Apt-GNPs. At very high PDGF concentrations, there was, again, no obvious aggregation (Scheme 2C). The formation of cross-links decreased as a result of repulsion and steric effects because the surface of the AptGNPs quickly became saturated with PDGF molecules through aptamer-PDGF binding. We have found that the PDGF-adsorbed GNPs (when saturated with PDGFs) are as stable (no aggregation) as BSA-adsorbed GNPs at high salt concentrations (>2 M; $\mathrm{pH}$ 7.4), mainly as a result of Coulombic repulsion. We note that the $\mathrm{pI}$ values for each of these PDGFs is $\sim 9.8 .{ }^{31}$
PDGF-AA-Induced Aggregation. The dispersed Apt-GNPs displayed an extinction band (surface plasmon resonance band) at $530 \mathrm{~nm}$, which underwent red shifts with decreased extinction (the extinction at $650 \mathrm{~nm}$ increased) upon aggregation. The extinctions at 650 and $530 \mathrm{~nm}$ are related separately to the quantities of the dispersed and aggregated Apt-GNPs. As mentioned previously, the degree of aggregation depends on the PDGF-AA concentration. At very high and very low initial PDGFAA concentrations, we observed no serious aggregation (Figures 1 and 2). Figure 1 indicates that the extinction at $530 \mathrm{~nm}$ shifted slightly to the red at $10 \mathrm{nM}$ and $400 \mathrm{nM}$ PDGF, with a distinct increase in the extinction at $\sim 530 \mathrm{~nm}$ that could be explained by the change in the dielectric constant of the GNP when its surface is largely covered with PDGF-AA units. At a GNP concentration of $8.4 \mathrm{nM}$, the total calculated concentration of aptamer was 353 $\mathrm{nM}$, based on 40 Apt molecules per GNP; this value is much higher than that of PDGF-AA (10 nM), and thus, no serious aggregation was observed. On the other hand, at high concentrations (e.g., $400 \mathrm{nM}$ ), there were enough PDGF-AA molecules to bind to all aptamers on the GNPs, which eliminates cross-linking (Figure 2D). At a PDGF-AA concentration of $75 \mathrm{nM}$, aggregation of the Apt-GNPs occurred, and the color changed from red to purple (Figure 1). The aggregation was also monitored by TEM (Figure 2C). We note that the GNP aggregates did not disperse upon adding more PDGF-AA (up to $400 \mathrm{nM}$ ) to the solution. The binding between PDGF-AA and Apt-GNPs is also supported by changes in the electrophoretic mobility of the Apt-GNPs. ${ }^{32}$ At 10 nM PDGF-AA, the electrophoretic mobility of the Apt-GNPs

(31) Antoniades, H. N.; Scher, C. D.; Stiles, C. D. Proc. Natl. Acad. Sci. U.S.A. 1979, 76, 1809-1831. 
A.

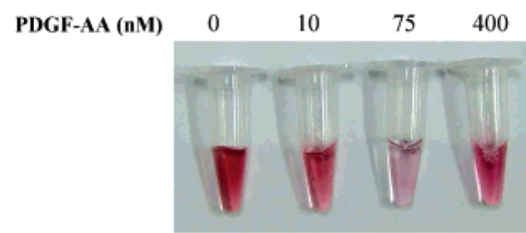

B.

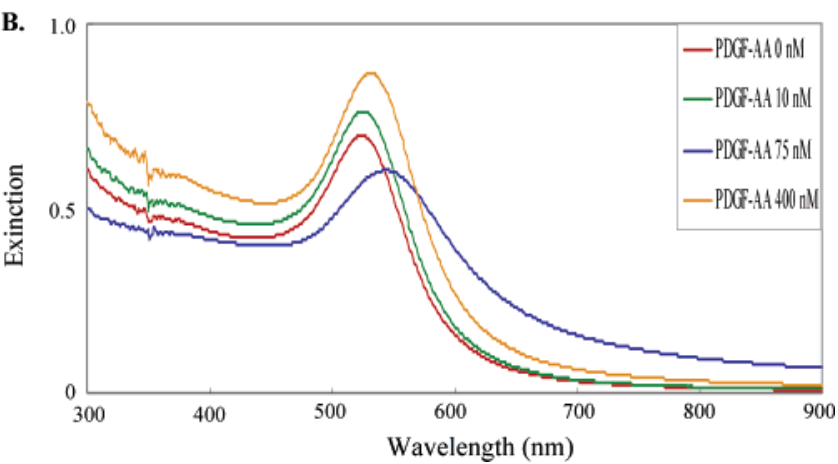

Figure 1. (A) Colors and (B) UV-vis extinction spectra of Apt-GNPs $(8.4 \mathrm{nM})$ in the presence of different concentrations of PDGF-AA in $5 \mathrm{mM}$ phosphate solution ( $\mathrm{pH} 7.4$ ) containing $200 \mathrm{mM} \mathrm{NaCl}$. The spectra were recorded after allowing the reactions to proceed for $2 \mathrm{~h}$.

A.

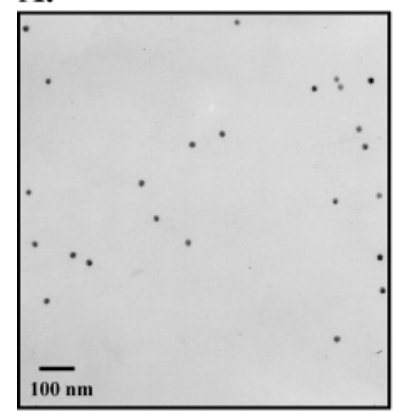

B.

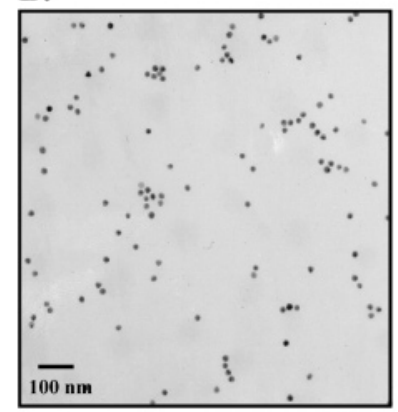

C.

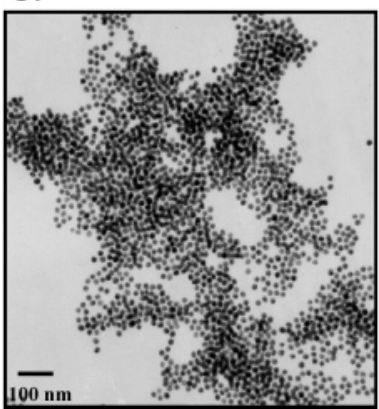

D.

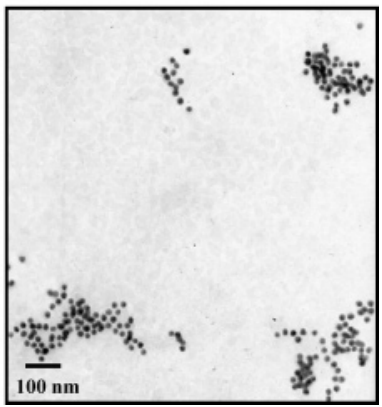

Figure 2. TEM images of the nanoparticles obtained from the solutions containing Apt-GNPs and PDGF-AA. PDGF-AA concentrations: (A) 0, (B) 10, (C) 75, and (D) $400 \mathrm{nM}$. Other conditions are the same as those described in Figure 1.

shifted from 3.00 to $2.78 \mathrm{~cm}^{2} \mathrm{~s}^{-1} \mathrm{~V}^{-1}$, which indicates that binding occurred between the Apt-GNPs and PDGF-AA. At 75 nM PDGF, many spiked peaks caused by scattering of the aggregated AptGNP clusters appeared in the electropherogram (see Figure S1 in the Supporting Information). At a higher PDGF concentration

(32) (a) Shimura, K.; Karger, B. L. Anal. Chem. 1994, 66, 9-15. (b) Chu, Y.-H. Avila, L. Z.; Gao, J.; Whitesides, G. M. Acc. Chem. Res. 1995, 28, 461-468. (c) German, I.; Buchanan, D. D.; Kennedy, R. T. Anal. Chem. 1998, 70, $4540-4545$.

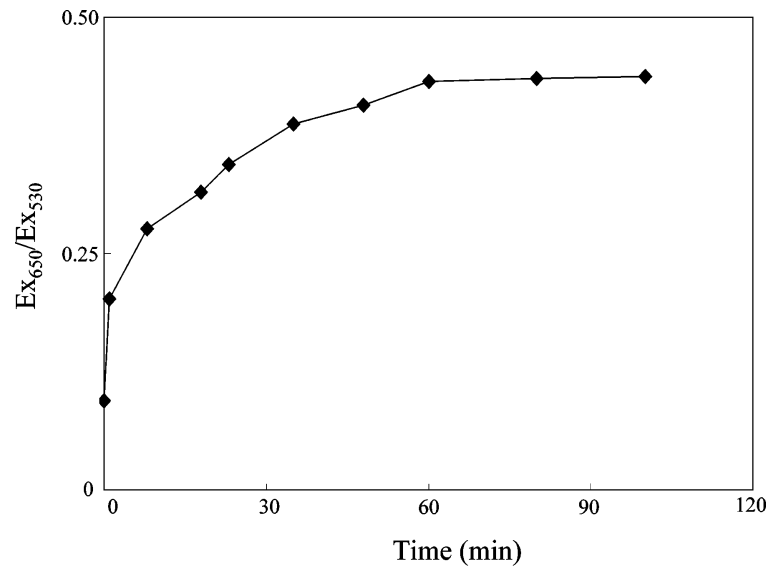

Figure 3. Evolution of the extinction ratio $\mathrm{Ex}_{650} / \mathrm{Ex}_{530}$ over time, recorded after the addition of $75 \mathrm{nM}$ PDGF-AA to Apt-GNPs (8.4 nM) in $5 \mathrm{mM}$ phosphate solution ( $\mathrm{pH}$ 7.4) containing $200 \mathrm{mM} \mathrm{NaCl}$.

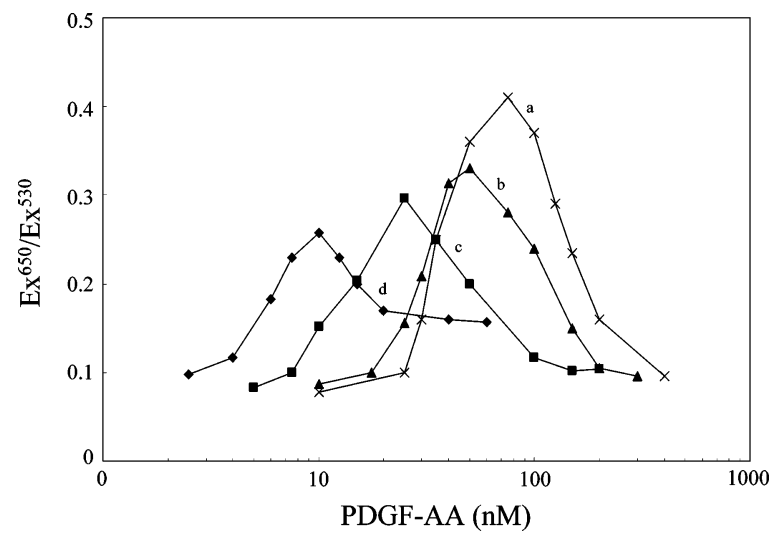

Figure 4. Calibration curves of PDGF-AA obtained using varying concentrations of Apt-GNPs. The concentrations of Apt-GNPs were (a) 8.4 , (b) 4.2 , (c) 2.1 , and (d) $0.42 \mathrm{nM}$. Other conditions are the same as those described in Figure 1.

(400 nM), only a small number of spiked peaks appeared in the electropherogram.

In this study, we used the extinction ratio $\left(\mathrm{Ex}_{650} / \mathrm{Ex}_{530}\right)$ to assess the degree of aggregation; this approach has been reported to be more accurate for analyte detection..$^{33}$ The extinction ratio is also associated with the color of the solution, with a high ratio corresponding to a purple solution and a low ratio, to a red one. Figure 3 displays the ratios of the UV-vis extinctions of the solutions containing Apt-GNPs and PDGF-AA and reveals the evolution of aggregation. The aggregation of Apt-GNPs induced by PDGF-AA required $\sim 1 \mathrm{~h}$ to reach completion. Figure 4 further displays the calibration curves of PDGF-AA using varying concentrations of Apt-GNPs. All of the calibration curves exhibit biphasic relationships; the extinction ratios $\mathrm{Ex}_{650} / \mathrm{Ex}_{530}$ reached maximum values at PDGF-AA concentrations of 10, 25, 50, and 75 when using $0.42,2.1,4.1$, and $8.2 \mathrm{nM}$ Apt-GNPs, respectively; their linear ranges of increased extinction ratios were 2.5-10 $\left(R^{2}=0.97\right), 5-25\left(R^{2}=0.98\right), 17.5-40\left(R^{2}=0.99\right)$, and $25-75$ $\mathrm{nM}\left(R^{2}=0.97\right)$, respectively. These results indicate that low concentrations of Apt-GNPs provide better sensitivity for PDGFAA. We also note that the linear regions of decreasing extinction

(33) (a) Liu, J.; Lu, Y. J. Am. Chem. Soc. 2003, 125, 6642-6643. (b) Liu, J.; Lu, Y. Anal. Chem. 2004, 76, 1627-1632.

Analytical Chemistry, Vol. 77, No. 17, September 1, 2005 

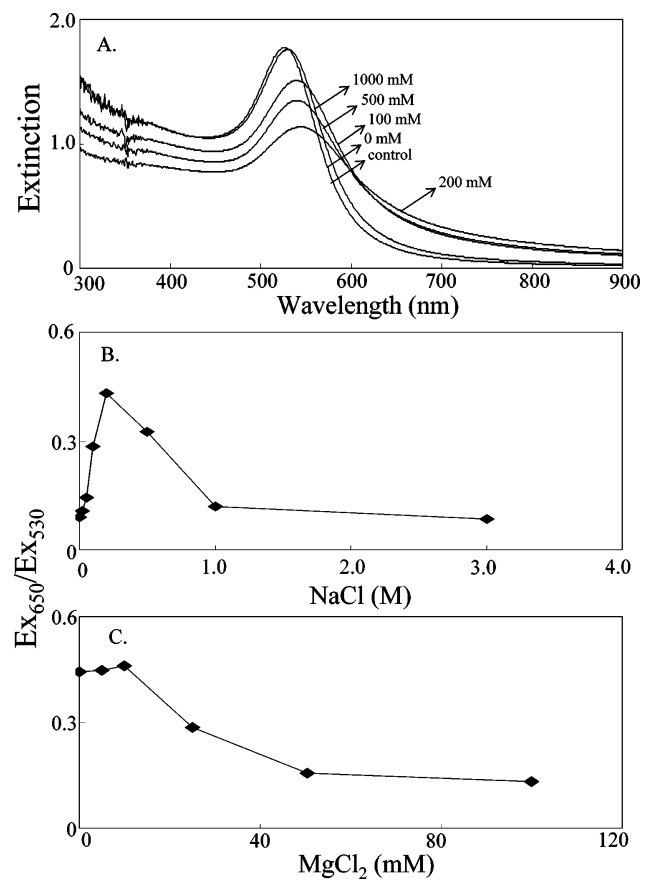

Figure 5. Effects of salts on the aggregation of Apt-GNPs in the presence of $75 \mathrm{nM}$ PDGF-AA. (A, B) UV-vis extinction spectra and plots of $\mathrm{Ex}_{650} / \mathrm{Ex}_{530}$ in $5 \mathrm{mM}$ phosphate solutions ( $\left.\mathrm{pH} 7.4\right)$ containing different concentrations of $\mathrm{NaCl}$. (C) Plots of Ex650/Ex 530 in $5 \mathrm{mM}$ phosphate solutions ( $\mathrm{pH} 7.4$ ) containing $200 \mathrm{mM} \mathrm{NaCl}$ and varying concentrations of $\mathrm{MgCl}_{2}$. All of the spectra were recorded $2 \mathrm{~h}$ after mixing the components. Other conditions are the same as those described in Figure 1.

ratios for curves a- $\mathrm{d}$ are useful for determining PDGF-AA in the concentration ranges $75-200\left(R^{2}=0.98\right), 50-200\left(R^{2}=0.98\right)$, $25-100\left(R^{2}=0.95\right)$, and $10-20 \mathrm{nM}\left(R^{2}=0.97\right)$, respectively. We point out that quantitative determination of the PDGF-AA in the two different regions can be achieved by conducting a standard addition method; the extinction ratios $\mathrm{Ex}_{650} / \mathrm{Ex}_{530}$ of the sample spiked with standard PDGF-AA are higher and lower than those of the sample in the increasing and decreasing regions, respectively.

Effect of Salt Concentration. The ionic strength of a solution usually has a significant effect on the binding of a single-stranded DNA (ssDNA) to a protein in aptamer-based assays. ${ }^{26,34} \mathrm{We}$ also note that the Apt-GNPs are stable in high-salt media (up to $4 \mathrm{M}$ ). To explore the effect of ionic strength on the PDGF binding assay, we performed a series of binding experiments in $5 \mathrm{mM}$ sodium phosphate buffer ( $\mathrm{pH} 7.4$ ) containing $0-3.0 \mathrm{M} \mathrm{NaCl}$ (Figure 5). Over the range of $\mathrm{NaCl}$ concentrations from 0 to $200 \mathrm{mM}$, the magnitude of aggregation of Apt-GNPs increased upon increasing the $\mathrm{NaCl}$ concentration. It is known that the conformation of DNA is highly dependent on the salt concentration, and the PDGFaptamer adopts a unique triple helix conformation upon protein binding. ${ }^{28,29}$ Moreover, the PDGF-AA-binding aptamer displays different hairpin structures at different salt concentrations; the conformation adopted by the aptamer in $200 \mathrm{mM} \mathrm{NaCl}$ is the most favorable one for PDGF-AA binding. ${ }^{28,29}$ In the range of $\mathrm{NaCl}$ concentrations from 0.2 to $3.0 \mathrm{M}$, however, aggregation of the

(34) (a) Fang, X.; Li, J. J.; Tan, W. Anal. Chem. 2000, 72, 3280-3285. (b) Jiang, Y.; Zhu, C.; Ling, L.; Wan, L.; Fang, X.; Bai, C. Anal. Chem. 2003, 75, 21122116. (c) Jiang, Y.; Fang, X.; Bai, C. Anal. Chem. 2004, 76, 5230-5235.

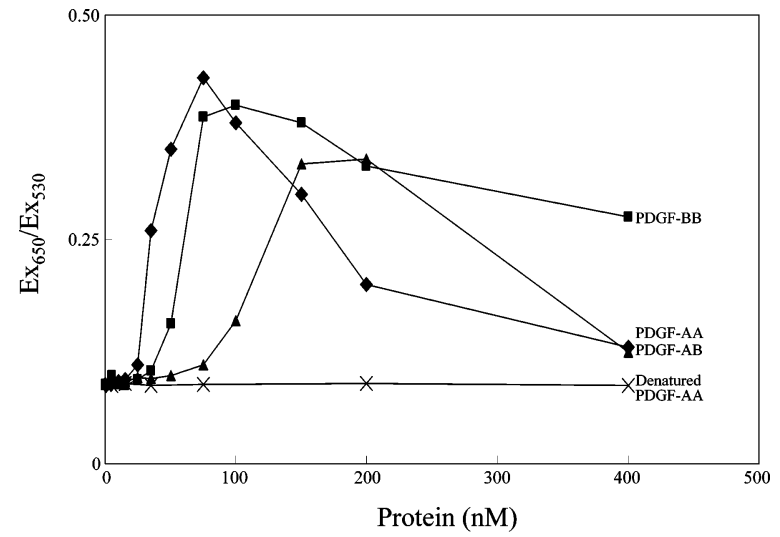

Figure 6. Validation of the use of Apt-GNPs as probes for PDGFs. Other conditions are the same as those described in Figure 1.

Apt-GNPs decreased upon increasing the $\mathrm{NaCl}$ concentration, which is a finding similar to that observed for the reaction between free ssDNA and proteins in solution. 26,34

We also investigated (Figure 5C) the effect that the $\mathrm{Mg}^{2+}$ concentration $(0-100 \mathrm{mM})$ has on the aggregation of Apt-GNPs in $5 \mathrm{mM}$ sodium phosphate $(\mathrm{pH} 7.4 ; 200 \mathrm{mM} \mathrm{NaCl})$. When compared to the effect of $\mathrm{NaCl}$, increasing the $\mathrm{MgCl}_{2}$ concentration has a greater effect on the disruption of Apt-GNP aggregation induced by PDGF-AA. Our results agree with prior observations that divalent ions, such as $\mathrm{Mg}^{2+}$, have a stronger impact on the binding strength of aptamers to proteins than do monovalent ions, such as $\mathrm{Na}^{+}$, in free solution. ${ }^{32 \mathrm{a}}$ This phenomenon is due mainly to the fact that $\mathrm{Mg}^{2+}$ has a greater affinity to the phosphate groups on the DNA backbone, and thus, it can more effectively neutralize the oligonucleotides.

Aggregation-Based Assays for PDGFs. Nonspecific binding is a critical issue when using nanomaterials for sensing macromolecules. To overcome nonspecific binding, we chose to add $0.1 \%$ BSA (see Figure S2 in the Supporting Information). The BSAmodified Apt-GNPs were stable in the presence of $\mathrm{NaCl}$ at concentrations up to $3.0 \mathrm{M}$. Unlike BSA, the addition of proteins, such as CA, Try, and Lys, that bind nonspecifically to the AptGNPs caused aggregation (data not shown). In contrast, these proteins did not cause aggregation of the BSA-modified Apt-GNPs, mainly because of Coulombic repulsion between the proteins and the BSA-modified surfaces. Figure 6 displays the results of the aggregation of Apt-GNPs in the presence of PDGF-AA, PDGF$\mathrm{AB}$, and PDGF-BB. When the PDGFs were denatured with sodium dodecyl sulfate and glycerol, the resulting protein failed to cause any aggregation of the BSA-modified Apt-GNPs. The result from one typical experiment (using PDGF-AA) is depicted in Figure 6. We found that the PDGFs did not cause any aggregation, either when no aptamer molecules were attached to the GNPs or when oligo-GNPs were used (data not shown). ${ }^{35}$ These results confirm that the aggregation of the Apt-GNPs that occurs in the presence of the PDGFs is due to specific binding of Apt to the PDGFs. The plots displayed in Figure 6 reveal that the BSA-modified AptGNPs have different sensitivities toward the PDGF isoforms. On the basis of the calibration curves, we could quantify PDGF-AA, $-\mathrm{AB}$, and $-\mathrm{BB}$ in the ranges of $25-75 \mathrm{nM}$ (increase) $(75-200 \mathrm{nM}$, decrease), 15-100 nM (100-400 nM), and 35-150 nM (150-

(35) Fang, X.; Sen, A.; Vicens, M.; Tan, W. ChemBioChem 2003, 4, 829-834. 


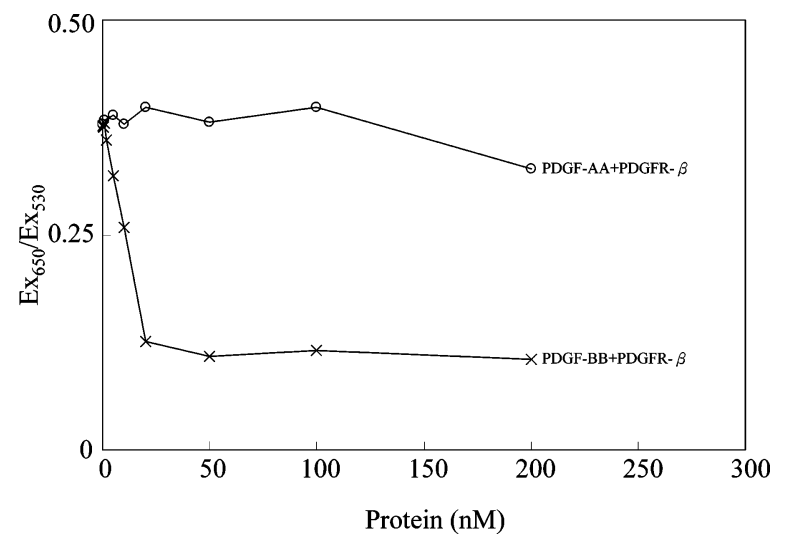

Figure 7. Competitive binding assay for determining the PDGF receptor- $\beta$ using the Apt-GNP probe. PDGF-BB and -AA were mixed separately with PDGFR- $\beta$ in $5 \mathrm{mM}$ PBS (pH 7.4) containing $200 \mathrm{mM}$ $\mathrm{NaCl}$ at room temperature for $1 \mathrm{~h}$ prior to reaction with the Apt-GNPs. The final concentrations of PDGF-BB and PDGF-AA were $150 \mathrm{nM}$ and $75 \mathrm{nM}$, respectively. The concentrations of PDGFR- $\beta$ and other control proteins were in the range $0-200 \mathrm{nM}$. Other conditions are the same as those described in Figure 1.

$400 \mathrm{nM}$ ), respectively. Interestingly, this order of sensitivities does not correlate with the stabilities of the Apt-PDGF complexes in free solutions: PDGF-BB > PDGF-AB > PDGF-AA. ${ }^{28}$ This result is likely due to changes in the structures of the aptamer molecules or the PDGFs on the GNP surface and differences in the nature of the nonspecific interactions between the PDGFs and the AptGNPs. We note that the molecular weights of PDGF-AA, -AB, and -BB are $2.9 \times 10^{4}, 2.7 \times 10^{4}$, and $2.5 \times 10^{4} \mathrm{~g} / \mathrm{mol}$, respectively.

Competitive Binding Assay for PDGF Receptor- $\beta$. It is known that aptamers can inhibit the binding of PDGFs to PDGFR and suppress the regulation of PDGFR. ${ }^{28,36}$ Therefore, we believed that addition of the PDGFR to solutions of the Apt-GNPs would alter the degree of aggregation. To test this hypothesis, we conducted a competitive assay using the Apt-GNPs. As indicated in Figure 7, the degree of aggregation of the BSA-modified AptGNPs induced by PDGF-BB reduced upon increasing the concentration of PDGFR $-\beta$. We stress that the impact that CA and Try had on the aggregation of the BSA-modified Apt-GNPs and PDGF-BB was negligible (data not shown). In addition, PDGFR- $\beta$ did not affect the interaction between the BSA-modified Apt-GNPs and PDGF-AA. These results reveal that the disruption of aggregation was due mainly to competition between PDGFR- $\beta$ and the Apt-GNPs for the PDGF-BB, which is in good agreement with the fact that the interaction of the aptamer with PDGF-BB affects the binding of PDGF-BB with PDGFR- $\beta{ }^{28,36}$ On the basis of the dose-response curve presented in Figure 7, we estimate the LOD

(36) Floege, J.; Ostendorf, T.; Janssen, U.; Burg, M.; Radeke, H. H.; Vargeese, C.; Gill, S. C.; Green, L. S.; Janjić, N. Am. J. Pathol. 1999, 154, 169-179. for PDGFR $-\beta$ to be $\sim 3.2 \mathrm{nM}$. The dose curve also reveals that this competitive assay allows the determination of PDGFR- $\beta$ over the concentration range from 0 to $200 \mathrm{nM}$, with minimum interference from proteins, such as CA, Try, and Lys. In addition, the Apt-GNPs are useful materials for the determination of PDGF$\mathrm{BB}$ in the presence of PDGFR $\beta$ without interference from PDGFAA. This competitive assay is simple, fast, specific, and sensitive.

\section{CONCLUSIONS}

We synthesized Apt-GNPs from 13-nm GNPs and $\mathrm{HOCH}_{3-}$ $\left(\mathrm{CH}_{2}\right)_{5} \mathrm{~S}-\mathrm{S}-5^{\prime}$-oligo (35-mer) and used them for the analysis of PDGFs and PDGFR- $\beta$. We have found that BSA is an effective substrate for passivating the Apt-GNP surface and, thus, minimizing any nonspecific adsorption of PDGFs. In 5 mM PBS (pH 7.4; $200 \mathrm{mM} \mathrm{NaCl}$ ), the Apt-GNP probe specifically and sensitively detected PDGFs with LODs at the nM level. By conducting a competitive assay, we realized the determination of PDGFR $-\beta$ using the Apt-GNP as a probe. The result of our competitive assay suggests that the selectivity of this method to PDGF isoforms can be improved by adding the PDGFRs to samples. For example, by adding excess amounts of PDGFR- $\beta$, only PDGF-AA induces aggregation of Apt-GNP. With the advantages of simplicity and specificity, the use of Apt-GNPs may be well-suited for protein analysis and cancer diagnosis, but preconcentration of PDGFs and PDGFR- $\beta$ is required when using our developed assay. Our study also demonstrates that the salt concentration and the nature of the surface of the nanoparticles are both important parameters in determining the sensitivity and specificity of aptamer-nanoparticle-based probes. Future efforts could be focused on developing aptamer-based probes using different types of nanomaterials, such as gold nanorods (GNRs), to enhance the sensitivity. To further improve the specificity and dynamic range of these aptamernanoparticle-based probes, it will be important to suppress the nonspecific adsorption of proteins and DNA by modifying the surface with biocompatible polymers, such as poly ( $N$-vinyl-2pyrrolidone).

\section{ACKNOWLEDGMENT}

This work was supported in part by the National Science Council, Taiwan (93-2113-M-002-035, 93-PFA-0100100), U.S. NIH grants, and a U.S. NSF NIRT Award.

\section{SUPPORTING INFORMATION AVAILABLE}

Electropherograms of Apt-GNPs recorded in the absence and presence of PDGF-AA. The changes in the ratio of $\mathrm{Ex}_{650} / \mathrm{Ex}_{530}$ in the presence of PDGF-AA (gray bars) and lysozyme (black bars) were plotted. This material is available free of charge via the Internet at http://pubs.acs.org.

Received for review May 31, 2005. Accepted July 7, 2005.

AC050957Q 